How Journalists Think about Media Effects-And Why We Should Care

\author{
Philipp Müller ${ }^{1} \&$ Ralf Hohlfeld ${ }^{2}$ \\ ${ }^{1}$ Department of Communication, Johannes Gutenberg University Mainz, Germany \\ ${ }^{2}$ Chair of Communication Studies, University of Passau, Germany
}

This is an authors' postprint of the article:

Müller, P., \& Hohlfeld, R. (2017). How journalists think about media effects-And why we should care. Atlantic Journal of Communication, 25, 88-100. doi: 10.1080/15456870.2017.1286343 


\title{
How Journalists Think about Media Effects—And Why We Should Care
}

\begin{abstract}
Research suggests that journalists' beliefs about media effects are influenced by unsystematically gathered knowledge and subjective-intuitive judgments. However, it has also been shown that these presumptions must be considered important factors for the formation of journalistic coverage. Against this background, this article synthesizes existing research on dimensions, determinants, and consequences of journalists' presumptions of media effects. The resulting framework offers researchers in the field of journalistic content production a comprehensive overview of the possible role that presumptions of media effects could play for journalistic content creation. In a second step, we summarize the implications that the current state of research points at. We discuss why journalism scholars should integrate presumed media effects into their research agendas and what communication researchers as well as journalists themselves could do to promote more realistic beliefs about media effects among journalists.
\end{abstract}

\section{Keywords}

Journalism, media effects, content production, influences on media content, influence of presumed influence. 
How Journalists Think about Media Effects-And Why We Should Care

The relationship between journalists and their audiences plays an important role for the understanding of news production (Schudson, 2000, p. 194). Many authors agree that journalists think about their audience in one way or another when producing media content. It has been argued that journalists, at least to a certain degree, try to match the (presumed) needs and expectations of the audience (e.g., DeWerth-Pallmeyer, 1997; Napoli, 2003; Schudson, 1978; Shoemaker \& Reese, 1996, 105-12; Witschge, 2012). However, media bias research suggests that journalists do not only think of their audience in terms of a customer they provide a service for but also as a group they intend to influence with their work in different respects (for an overview, see Lee \& Grimmer, 2013). That said, it seems important to understand how journalists think about media effects. Their presumptions about the mechanisms behind media effects might be an important influence on many journalistic decisions during the publication process.

While several studies have already engaged in measuring journalists' cognitions about media effects and exploring their consequences, yet there is no synthesis of the existing research that discusses the practical implications of what is known so far. The present article aims at this task. It proceeds in two steps. First, we summarize the current state of research about dimensions, determinants, and consequences of journalists' presumptions about media effects. For this purpose, we combine theoretical ideas and empirical findings from existing research with new thoughts on the subject matter. This leads to an integrated model of dimensions, determinants, and consequences of journalists' presumptions about media effects that is intended to serve as a framework for empirical research. It identifies analytical categories which should be considered in future studies. In the second step, we discuss the societal implications of the existing research. This seems especially relevant since results 
indicate that journalists might be insufficiently informed about media effects and that their publication decisions might thus be based on biased perceptions of media effects. We look at this problem from two different perspectives. We discuss why and how journalism scholars should integrate presumed media effects into their research agendas and what communication researchers as well as journalists themselves could do to promote knowledge transfer from academic media effects research to the journalistic field.

\section{Dimensions of Journalists' Presumptions about Media Effects}

Journalists' presumptions about media effects can be understood as "subjective theories" (Groeben, 1990), i.e., inter-individually different mental representations of the world that can be crucial starting points for different forms of human behavior (on subjective media theories in particular see, e.g., Seiter, 2003). It is important to note that these presumptions can differ in terms of quality. That means that different cognitions describe social reality differently well. Many authors distinguish between lay theories and scientific theories (see, e.g., Furnham, 1988). Expert theories of practitioners such as journalists are then deemed to lie somewhere in between (MacDougall, 2003). Journalists' knowledge about media effects should, thus, be more sufficient than that of complete laypersons but less than scientific theories. However, such a classification seems over-simplistic. Instead, it can be assumed that there is a qualitative continuum of subjective theories with completely insufficient lay theories at the one end and highly systematic and valid knowledge at the other end of the scale (Furnham, 1988, p. 208). Just as scientific theories may not per se reach the highest possible level of system and validity — merely because they are scientific — lay theories and practitioners' expert theories are not automatically less systematic and valid (Kruglanski, 1989, pp. 223-246).

A higher quality of presumptions about media effects is also related to a higher complexity and range. Do journalists merely have vague notions of an influence of the media 
or do they think in more complex and concrete terms, perhaps even differentiate between diverse causes, consequences or even third variables of media effects? While media effects research itself deals with complex models of media influence and sophisticated middle range theories, the investigation of presumed media influence mostly remains on the level of quite general assumptions. Respondents are often asked to estimate the strength of a presented media stimulus or the media in general on themselves, the population at large or other more specific groups of people (for a summary, see Andsager \& White, 2007). This presumed strength is moderated by the evaluation of the social desirability of the media influence in question (Eveland \& McLeod, 1999). This suggests that researchers—at least implicitlyassume that laypersons do not develop complex and sophisticated assumptions of media effects. Rather, they seem to imply that laypersons merely think in the comparatively simple categories of the strength and desirability of media effects.

Consequently, most of the studies that investigate journalists' presumptions of media effects also mainly deal with these two categories. In early journalism surveys, participants were very generally asked to assess the strength of media influence on public opinion as one aspect among many others (Donsbach, 1983, p. 31; Weaver \& Wilhoit, 1986, pp. 142-143). More recent research investigates journalists' third-person perceptions, i.e., the difference between presumed strength of media influence on self and others (Bernhard \& Dohle, 2014; Dohle \& Vowe, 2010; Tsfati \& Livio, 2008). These studies are designed as quasi-experiments and test for differences in third-person perceptions between journalists and other groups of people. They point to an important aspect as they distinguish between descriptive and evaluative propositions of media effects which might both contribute to shaping journalists' production decisions. But, the studies still operate at a very general level instead of comparing presumptions about different forms of media influence. 
This route is tackled by Lee and Chan (2009) and Li (2013), who ask journalists in Hong Kong to assess the strength of different types of media influence on the public and in politics. Lee and Chan (2009) find that media influences on political attitudes and on citizens' political mobilization are estimated significantly stronger than media influences on social grievances, on suicidal behavior, or on politicians' behavior and government policy. A survey among German communication technology journalists (Geiß, Jackob, \& Quiring, 2013) takes a similar direction and shows that these special interest journalists assume that their product reviews have a considerable influence on different consumer behaviors (further information search, detention of purchase decisions, and cancellation of purchase decisions already made).

However, such area-specific journalistic presumptions of media effects are still not necessarily complex. It would be worthwhile to explore the existence of more elaborate presumptions of media effects as well as their presumed constraints and causalities. Journalists might form subjective theories of media effects in the sense of Groeben (1990) which also refer to different causes and consequences of media effects, and thus are not merely descriptive or evaluative but also explanatory. Different more specific notions of media effects within the same individual might even contradict each other. One or the other presumption about media effects could be salient in different situations. Future research should attempt to detect journalists' sets of specific presumptions about media influence. There seems to be an imbalance between the nuanced and complex theories of media effects research, such as cultivation, agenda-setting, or persuasion, and the very general way in which journalists' presumptions of media effects are studied. It remains unclear whether journalists develop perceptions of media effects that resemble (or mirror) the academic theories or whether they even form theories of media effects that academic research has not yet considered. 
Therefore, an investigation of more elaborate presumptions about media effects seems necessary. A first step in this direction could be made with qualitative interviews and group discussions that identify the media effects mechanisms journalists assume. Such research could also examine at which levels journalists' presumptions of media effects are situated. Journalists might be able to distinguish between media effects on the individual and societal level (Chaffee \& Berger, 1987; Pan \& McLeod, 1991): Journalists should have an idea of the difference between media-induced social change and media effects on the individual. It would be interesting to see how journalists balance these two levels against each other. Media messages that might have beneficial effects for individual users could have negative social consequences (and the other way around). Therefore, research should consider whether journalists distinguish between the two levels and how they think about them together.

\section{Determinants of Journalists' Presumptions about Media Effects}

\section{Information sources}

The most important determinant of journalists' presumptions of media effects are probably the information sources on which they are based. The question where journalists' assumptions come from has a massive influence on the complexity, system, and validity of these assumptions. Generally, journalists' beliefs about the audience can emerge in two ways: (1) it can be based on available information about the audience (e.g., from market research or from direct feedback such as commentaries on news websites) or (2) it could stem from intuitive and not at all empirically grounded presumptions and projections. Several authors have criticized that journalists' actual knowledge of and contact with their audience is very limited (e.g., Burgoon, Burgoon, Buller, \& Atkin, 1987; Gans, 1979; Schlesinger, 1978). This leads to the assumption that intuitive judgment contributes to the formation of journalists' audience beliefs to a considerable extent. The resulting impressions are probably not of a very 
high quality in terms of system, validity, and complexity. They might even be described as “newsmen’s fantasies” (Pool \& Schulman, 1959)

However, there are sources that could give journalists a reliable impression of the audience - first and foremost the results of market research and academic audience research. Also, journalists could rely on direct encounters with audience members, letters to the editor, audience calls, and different kinds of online user feedback (Coleman \& Ross, 2010, pp. 52 71). But direct audience feedback is less informative than research results because only "selected parts of the audience" (Loosen \& Schmidt, 2012, p. 871) engage in such a behavior. Audience feedback necessarily does not offer the whole picture. A German journalist survey $(n=418)$ shows that journalists indeed regard sources such as letters to the editor $(78.3 \%)$, personal encounters with audience members $(77.3 \%)$ or audience calls $(70.2 \%)$ as important factors for the emergence of their audience image (Hohlfeld, 2003, pp. 256-263). However, such arbitrary and unsystematic direct contacts might result in a biased picture. Concerning research results the study unveils a gap: while many journalists consider the results of applied media market research (74.2\%) an important source for their audience image, hardly any of them concern themselves with the results of academic communication research (9.3\%). From this it can be concluded that journalists will probably have a well-balanced idea of how their audience is composed and what it looks for in a media product since these questions are answered by market research. But, they will probably have scarce reliable information about the effects of their work on the audience which is only provided by academic research.

This is highly problematic since it means that journalists' presumptions about media effects are mostly based upon intuitive everyday reasoning and arbitrary cues that can originate from a number of sources. Among these, conversations with colleagues should be an important factor. Research has shown that journalists' attitudes and decisions strongly depend on co-orientation (Gans, 1979; Shoemaker \& Reese, 1996, pp. 105-138). The same has been 
found for journalists' audience image (Donsbach, 1981). It seems likely that journalists exchange their thoughts about media effects, especially among colleagues within the same organization. Besides, also conversations with members of their private social environmentand observations of these persons during media exposure - will probably receive special attention (Hartmann \& Dohle, 2005, p. 290). This almost necessarily results in large blind spots in the knowledge about media effects. If journalists mostly gain their ideas about media effects from talking to and observing individuals who are similar to themselves in terms of sociodemographics, political attitudes, lifestyles etc. they do not arrive at an impression that is representative for the whole society. Moreover, observing others and talking to them does not inform journalists about the intra-individual cognitive and emotional processes that take place during media exposure. These processes are barely observable from the outside and are also not articulated in most cases. They may even occur subconsciously.

Therefore, it must be assumed that journalists also form parts of their presumptions of media effects based on a projection or "looking-glass perception" (Fields \& Schuman, 1976). In lack of knowledge about other individuals' cognitions and emotions they could fill this black box with their own experiences as a media user and their introspective observations during media exposure on other audience members. This means that journalists' presumptions about media effects on the audience might in large parts depend on their perceptions of media effects on themselves (Shen, Palmer, Mercer Kollar, \& Comer, 2015). Also, the mere existence of media outlets or messages or, more specifically, the knowledge about their amounts of users could result in presumptions about effects. Such an "exposure-is-effect heuristic" (Sun, Shen, \& Pan, 2008, p. 260) is built on a magic-bullet logic that assumes direct interrelations between the exposure to a media message and its effect on the audience (Eveland, Nathanson, Detenber, \& McLeod, 1999). So to wrap it up, there is a variety of 
sources that journalists probably rely upon when reasoning about media effects that might offer them a biased picture.

\section{Epistemic motivation and cognitive mechanisms}

But information sources are not the only possible origins for biased presumptions about media effects. Which of the numerous accessible information sources is given more or less weight depends on the individual journalists' information selection and processing. Cognitive psychology assumes that there are two key factors in human information selection and processing: the cognitive mechanisms that are applied and the underlying motives of reasoning (Kruglanski, 1989, pp. 13-22). The epistemic motivation should have a considerable influence on the choice of information sources. A journalist who has a high intrinsic or externally induced motivation to learn about media effects (e.g., because this is expected by superiors) will probably put more effort into finding reliable information on media effects. Someone who only deals with the topic peripherally, on the contrary, may use the most easily accessible or most salient information (Kruglanski, 1989, pp. 66-68) that results, e.g., from observations in the private social environment or from direct audience feedback.

The epistemic motivation will also be an important factor in the way information is processed. The two-process models of information processing (Chaiken, Liberman, \& Eagley, 1989; Petty and Cacioppo, 1986) suggest that factors such as need for cognition or personal involvement determine whether incoming information is processed in a more superficial heuristic way or in a systematic manner. Therefore even journalists who use similar information sources might arrive at very different conclusions about media effects, depending on how they deal with the information they receive. Low cognitive motivation probably supports judgments about media effects that are based on heuristic cues rather than on 
thoughtful consideration. Nevertheless, these judgments can become important factors for journalists' message production.

In the motivational context, also consistency theory might play an important role (Kruglanski, 1989, pp. 85-110). Tsfati and Livio (2008, p. 115) have pointed out that journalists have to assume a certain positive influence of the media (or at least of their very own coverage) in order to maintain a positive self-image. Otherwise, their whole professional occupation would appear pointless. To assume the existence of a (desirable) media influence on society seems a necessity for journalists in order to justify the effort they put in their work (Aronson \& Mills, 1959). On the contrary, research points in the direction that experts in a specific field tend to overestimate negative media influences in their specific area of expertise (Price \& Tewksbury, 1996). For journalists, this is true on two counts. Not only are they experts in their specialized field of coverage (politics, culture, sport, etc.), they are also experts when it comes to the media's mechanisms of reality construction. These two alternative mechanisms make it hard to predict under which circumstances journalists will assume negative or positive media effects. It is thus important to further explore how journalists evaluate the impact of their own coverage and of the media in general in different contexts.

\section{Organizational and societal context}

When talking about journalistic work the picture cannot be complete without considering the organizational and societal background of the individual journalist see, e.g., Shoemaker \& Reese, 1996). It has already been pointed out that journalists' professional socialization and their professional social environment plays an important role for the formation of presumptions about media effects. Studies have demonstrated that the degree of audience orientation in journalism varies among editorial departments, publishing companies, types of media, or hierarchical levels within an organization (Hohlfeld, 2003; Meyen \& 
Riesmeyer, 2009). It can be assumed that presumptions of media effects vary accordingly. Research has, e.g., shown that ICT journalists in a higher hierarchical position more strongly believe that their audience reverses buying decisions based on their coverage (Geiß, Jackob, \& Quiring, 2013).

Beyond the organizational context, also the broader professional environment could give journalists an idea of (strong) media effects. Journalists are constantly confronted with public relations' attempts to influence their coverage. From this, they can deduce that business companies or non-profit organizations of all kinds, assume a certain influence of their work on the public. This could encourage journalists to assume strong media effects.

Along with professional socialization, academic socialization is an important factor in the formation of presumptions about media effects. Journalists who have studied communication, journalism, or a similar discipline should have been extensively confronted with the results of scientific research on media effects. This should put them in the position to form more valid presumptions about media effects in comparison to journalists who did not study communication. However, the question remains whether those who have an academic background in the communication field try to stay up-to-date by regularly reviewing recent research findings. For one thing, the knowledge acquired during the course of study might become outdated so that presumptions about media effects that build upon it become outdated, too. Apart from that, the academic knowledge might also simply fade away over the course of time if it is not regularly activated. For both reasons, it seems necessary that even journalists with an academic background in communication regularly stay in touch with media effects research.

\section{Consequences of Journalists' Presumptions about Media Effects}

How journalists think about media effects is relevant because it could have various consequences. Following an action theoretical approach (see, e.g., Coleman, 1990) it can be 
argued that human action — as long as it is not habitual and follows an automated script—is based upon an individual's presumptions about the social environment that are cognitively salient during the respective action sequence. Since the audience is the direct reference group of journalistic action, it can be argued that presumptions about the audience play an important role for journalists' content production. These presumptions can either deal with the needs and expectations of the audience or with the effects of journalists' work on the audience. It has to be expected that such presumptions influence journalists' coverage in one way or another (as will be explicated in the course of this article). Journalists' presumptions of media effects should thus be an important factor in content production. Since journalists' coverage fulfills quite a range of societal functions (see Christians, Glasser, McQuail, Nordenstreng, \& White, 2009) it is important to understand how presumptions of media effects contribute to this coverage.

Research has demonstrated that within the general population presumed media influences (Gunther \& Storey, 2003) and, more specifically, the so called "third-person perception" (Sun, Shen, \& Pan, 2008) have numerous consequences. They reach from effects on the processing of received media messages (Scherr, Müller, \& Fast, 2003), to behavioral intentions such as strategic voting (Cohen \& Tsfati, 2009) and the willingness to speak out in public (Mutz, 1989). The most prominently discussed effect in the literature is that thirdperson perceptions increase the support for media censorship. This effect has been demonstrated for journalists, too (Bernhard \& Dohle, 2014). The same could be true for other behavioral consequences that have been so far only been investigated among the general population. Where it really gets interesting is when these consequences touch on journalists' work and its outcomes.

One aspect that is already pretty well explored is how presumptions of media effects affect journalists' attitudes towards professional roles and norms. Tsfati and Livio (2008, pp. 
115-116) assume that journalists who believe in strong (negative) media effects on the public are more conscious of their professional responsibility and, therefore feel more strongly attached to professional norms and ethical standards. The authors test this hypothesis with data from an Israeli journalist survey and find that the perception of strong media effects on public opinion significantly correlates with a conservative journalistic role image and with the perceived importance of journalistic neutrality and distance to the object of coverage. Strong third-person perceptions are, in turn, related to a liberal role image (Tsfati \& Livio, 2008, 122). Lee and Chan's (2009) and Li's (2013) surveys of Hong Kong journalists yield similar findings. Both studies show that presumptions of strong media effects generally bolster the approval of journalistic professional norms.

This amplification of professional ethical standards through presumptions of strong media effects could indirectly influence the formation of journalists' coverage in different ways. Berkowitz and Limor (2003) have demonstrated that journalists' work-related ethical convictions have the power to influence their publication decisions and lead them to a more ethical behavior. However, these effects depend on the situational context and are specifically affected by organizational imperatives. Thus presumptions of strong media effects do not necessarily have to result in a more conscientious coverage, even if they increase ethical standards in a first step.

Beside these rather positive consequences of presumptions of strong media effects on ethical decisions within journalism, also more problematic consequences are conceivable. The idea that their work is in one way or another able to change the audience's attitudes, emotional states or behaviors could reinforce journalists with a more missionary role perception (see e.g., Hanitzsch, 2011; O’Sullivan \& Heinonen, 2008; Weaver \& Wilhoit, 1986) in their attempts to influence the audience through their coverage. Such an effect would be in line with the basic assumption of news bias research that journalists try to influence the 
audience in favor of their own political convictions (see e.g., Hofstetter, 1976; Kepplinger, Brosius, \& Staab, 1991). More complex subjective theories of specific media effects mechanisms and the success of different persuasive strategies could guide journalists' behavior in this context. However, the relationship between the assumptions of news-bias research and journalists' presumptions of media effects has not been investigated empirically so far. Studies that intend to do so should recognize the empirical relationship between presumed media effects and professional ethical orientations that point in the direction of positive effects. Ideally, studies would compare both directions in which journalists' presumptions about media effects on the audience could influence coverage.

Moreover, it has also been suggested that presumptions of reciprocal media effects (Kepplinger, 2007) on the groups that are subject to journalists' coverage (e.g., politicians, athletes, artists or businessmen) could lead to an increase in attempts to influence these groups. More specifically, research suggests that political journalists' coverage could be related to their presumptions of media effects in politics and on politicians (Dohle \& Vowe, 2010; Lee \& Chan, 2009; Li, 2013; van Aelst et al., 2008). When journalists recognize that their coverage provokes politicians to respond and react or when they observe policy changes in reaction to media coverage (Yanovitzky, 2002) this might reinforce them in reporting in a critical tone towards policy and politics. If journalists, on the contrary, observe that critical media coverage does not significantly impact political decisions they might be disencouraged to further engage in critical coverage. Therefore, future research should continue to investigate journalists' presumptions of reciprocal media effects, especially in politics.

On a minor note, journalists' presumptions of media effects also influence media's reporting on media and their effects and societal functions (see, e.g., Müller, 2013). Despite the fact that it may seem generally opportune for journalists to publicly downplay media effects within society (Noelle-Neumann, 1982), they should nevertheless be reflected in 
media coverage about media. Research has, e.g., demonstrated that traditional media's framing of media innovations often over-exaggerates their possible positive and negative consequences (see, e.g., Rössler, 2001). Such portrayals are probably closely related to journalists' belief about the respective new media technologies and their effects.

Another imaginable consequence concerns journalists personally. It has been shown for other groups of professional communicators (for politicians: Cohen, Tsfati, \& Sheafer, 2008; for scientists: Tsfati, Cohen, \& Gunther, 2011) that presumptions of strong media effects lead people to strive for an intensified self-presentation in the media which is also related to a greater amount of actual media attention. Such effects might also occur among journalists. Certain presumptions of media effects could lead journalists to put a stronger emphasis on their own person and their self-presentation. They could, e.g., support their decision to engage in personal branding on social media platforms (Molyneux, 2015). Differences regarding such behaviors could be moderated by introversion/extraversion or the degree of striving for social acknowledgment.

\section{[Figure 1 about here]}

\section{How Journalists Think about Media Effects: An Integrated Model}

Figure 1 summarizes the dimensions, determinants, and possible consequences of journalists' presumptions about media effects that have been discussed so far. We have argued that a range of different information sources can help journalists to arrive at their impressions of media effects. Based on an individual's epistemic motivation, the information from these different sources is selected and cognitively processed either in a thorough and systematic way or in a more heuristic manner that does not require as much cognitive effort. This cognitive process results in a set of different, maybe even contradictive, presumptions of 
media effects. These presumptions differ regarding their system and validity, complexity and range. Three different types of proposition have been identified (descriptive, evaluative, and explanatory). Furthermore, the different propositions can either aim at media effects on the individual or the societal level, or they can even describe relationships between individual and societal media effects. A number of consequences of these different presumptions about media effects have been discussed. Some of them could be mediated through attitudes of professional roles and norms. Studies have shown that these attitudes are connected to presumptions about media effects and that they can affect journalists' decisions to be more conscientious and ethically oriented. However, journalists' presumptions about media effects could also motivate attempts of influencing the audience or other groups of actors within society in specific ways. They could, e.g., promote a more critical coverage of politics. Moreover, they should also be reflected in coverage about the media themselves and their role in society and they could enhance journalists' strive for self-presentation.

All of these individual-level processes are embedded in a broader social environment that is being defined by the organizational context and the society at large. Especially the individual journalists' professional and academic socialization could be important factors in the formation of presumptions about media effects.

The model appears to describe a unidirectional process. But it could end in a cycle. Journalists' coverage, which is formed under the influence of presumptions about media effects, could for instance provoke audience feedback that could serve as additional information about media effects in a next step. Moreover, we have argued that the mere existence of media messages and knowledge about the audience's exposure to these messages could function as a heuristic indicator of effects. Therefore, journalists might assume media effects based simply on the coverage that they themselves and their colleagues produce. 
The current state of research on journalists' presumptions about media effects unveils two main reasons for thinking about its practical implications: First, studies have demonstrated that journalists' conceptions of media effects could have considerable consequences for their work. It has been shown that presumptions of strong media influences can lead to a higher sensitivity for professional norms and ethics (Lee \& Chan, 2009; Li, 2013; Tsfati \& Livio, 2008). But they could also encourage and guide journalists who see it as their task to change society for the better (Hanitzsch, 2011) in their attempts to influence the audience as well as other actors, e.g. policy-makers. This has not yet been assessed empirically. But, based on the arguments of news bias research it should at least be taken into account. Taken together, these considerations suggest that presumptions of media effects could be an important factor in the emergence of journalistic coverage that is yet to be fully explored by journalism research.

Consequently, it seems important to understand how journalists think about media effects and where their ideas on the subject matter come from. Survey data (Hohlfeld, 2003) suggest that journalists form their audience image based mainly on arbitrary direct audience contacts and on the results of market research. Academic audience research does not seem to play an important role as a source of information about the audience. This suggests that many journalists have a high epistemic motivation (Kruglanski, 1989) to learn about the wishes and needs of their audience. They seem to be motivated to look for reliable information on these questions and find it in market research. This is not very surprising. Journalists' job safety and personal income depends on the circumstance that the journalistic product they contribute to finds its audience (Napoli, 2003). It is therefore of vital significance for journalists to have an idea about what their audience wants. This knowledge can be acquired from market research.

However, market research cannot tell journalists anything about media effects. Systematic insights to this field are only provided by academic media research which is rarely 
taken into account. This means that journalists' presumptions of media effects are mainly based on information from direct audience contacts. Additionally, journalists could also project their own media usage experiences upon the general audience or rely upon heuristic indicators such as the "exposure-is-effect heuristic" (Sun, Shen, \& Pan, 2008, p. 260). We have argued that these sources are far from offering valid and systematic information about media effects. Moreover, the choice of sources suggests that, contrary to the needs and desires of the audience, journalists do not seem to be very motivated to arrive at a complete and valid picture of media effects. As a result, not only information selection but also information processing on the topic of media effects should be rather unsystematic and rely upon heuristic reasoning. This is problematic because it means that journalists' ideas about media effects might be flawed.

At the same time, this does not mean that presumptions about media effects are unimportant for journalists' message production. Even though their ideas about media effects are probably unsystematically gathered, journalists might still consider them consciously or subconsciously in their work. In fact, it seems highly unlikely that they are not interested at all in the possible consequences of their work. As mentioned above, several studies suggest relationships of presumptions about media effects and journalists' work. Against this background, the conclusion that journalists' presumptions about media effects seem to rely upon unsystematic sources and heuristic information processing is worrisome. It has several practical implications for both the investigation of audience production in journalism research and for knowledge transfer from media effects research to the journalistic field.

\section{Implications for journalism research}

The basic take-home message for journalism researchers is that while there is ample justification to consider presumptions about media effects as a factor in journalists' content production there is not enough research that actually does so. Many of our conclusions in the 
present article had to be drawn by analogy or based on theoretical considerations. More research is necessary regarding all aspects of journalists' presumptions about media effects that have been discussed in the present article.

Looking first at the dimensions of journalists' presumptions about media effects, we have seen that most of the existing studies have investigated them with quantitative surveys and on a high level of abstraction (strong vs. weak effects). Further exploration of the forms and contents of media effects beliefs is necessary. Research should start with qualitative interviews that identify different elements of journalists' sets of media effect beliefs and their interrelationships. A more detailed picture of the specific media effects mechanisms that journalists assume is required. In a second step, quantitative research should try to determine the prevalence of the respective presumptions. Turning to their determinants, evidence points in the direction that media effect beliefs could be based mainly upon insufficient indicators and heuristic judgment. However, a more exhaustive exploration of the sources for journalists' presumptions about media effects and the epistemic motivation that lies behind their formation is necessary. Experimental studies, think-aloud interviews, or in-depth interviews could be used to gain insight into information processing in this field.

Finally and most importantly, journalism research should aim at extending our knowledge about the consequences of journalists' presumptions about media effects. Most of the ideas that have been discussed in the present article have not been examined empirically yet. In order to identify relationships between presumptions of media effects and journalistic content production, studies could combine surveys and content analyses on an aggregate level. Or they could use surveys that ask journalists about their media effects presumptions and their behavioral intentions and work routines. This approach is quite common in research on the consequences of presumed media effects. However, its external validity has been criticized (e.g., Perloff, 1999, p. 368). 
In summary, the empirical examination of the questions raised in this article is not an easy task. However, especially the relationships between journalists' presumptions of media effects and their attempts to influence or persuade the audience should be explored. That is not to say, of course, that we assume a majority of journalists to have bad intentions which could be reinforced by media effect beliefs. For one thing, research has already demonstrated that presumptions of strong media effects can make journalists more responsible. Beliefs about media effects could also lead journalists to more strongly or more successfully engage in activities that are socially functional from a normative point of view, e.g. the control and critique of policy-makers (Christians et al., 2009). However, if these assumptions were flawed the outcomes could be dysfunctional nonetheless. Moreover, some journalists could pursue objectives that might not be socially desirable and could be driven by their media effects beliefs in this context. That is why it is important to extend knowledge about the causes and consequences of journalists' presumptions of media effects.

\section{Implications for knowledge transfer}

On the flipside, communication scholars are not only responsible for investigating how journalists produce media content but also how that content affects the general audience and more specific actors, for instance politicians. Having argued that journalists' presumptions about media effects might be flawed due to heuristic reasoning it is our societal responsibility as a scientific field, to more actively engage in knowledge transfer to the journalist profession. At this task, communication research should not content itself with the education of future journalists in academic programs. We have argued that the knowledge gained at university probably fades away over the life course. Moreover, although a growing number of journalists in many countries has in fact studied communication large parts still have not. That is why media effects researchers should actively seek contact to the journalist profession and offer easily accessible information about the current state of media effects 
research. First and foremost, this means to translate academic research papers into everyday language summaries and to circulate them among journalists. But it could also mean to offer specific trainings and courses in media effects research for professional journalists.

Journalists should at the same time recognize the importance that their own conceptualizations of media effects might have for their work and its societal impact. This should motivate them to more actively search for reliable information about how, why, and when which media effects actually occur. Journalists who have been trained in communication could fulfill an opinion leader function in this context. They should try to stay up-to-date with the current developments of academic media effects research and help their colleagues gain access to this knowledge. To sum it up, knowledge transfer is always a twosided task. Journalists as well as media effects scholars should try to approach one another in order to ascertain a successful flow of insights from academic media effects research to the domain of journalism.

\section{Conclusion}

In the present article, we have reviewed the current state of research on journalists' presumptions about media effects. The result is twofold: We have developed an analytical framework of the dimensions, determinants, and consequences of these presumptions within which future empirical work can be conducted. Moreover, we have discussed the practical implications of what is known so far. Our literature review has demonstrated that journalists' presumptions about media effects constitute a field of research that still has a remarkable amount of research gaps but also numerous connections with existing research from different areas of communication studies. Its social relevance and the large number of open research questions make further investigation of the matter within the field of journalism research necessary. At the same time, we are also dealing with a research subject that can be influenced directly by communication scholars. When we know about the insufficiencies of 
journalists' presumptions of media effects and their consequences, we can attempt to reach current and future journalists and supply them with more sufficient knowledge about media effects. Such knowledge transfer is a two-sided task to which journalists also should contribute.

Most of the considerations in this article have remained within the theoretical borders of unidirectional linear mass communication with clearly defined communicator and recipient roles. It appeared reasonable to us to stick to this limited frame for the first systematic outline of this field of research because this allows for clear classifications and reduces the complexity of the task. However, future steps must integrate the dynamic user and producer roles of online environments (see, e.g., Bruns, 2008). Today, it is daily routine for many media users to produce their own content, be it in the form of short commentaries and tweets or as complete blog entries. This changes the game between journalists and their audience (Loosen \& Schmidt, 2012; Yeo, 2016). User-generated content could serve as a new source of information about media effects for journalists. Also, knowledge about media effects might become more important to journalists in the new competitive situation of the Internet where an increasing number of actors contributes to media content. This could change the way journalists approach information on media effects. These are questions that future research needs to address. 


\section{References}

Andsager, J. L., \& White, H. A. (2007). Self versus Others. Media, Messages, and the ThirdPerson Effect. Mahwah, NJ: Erlbaum.

Berkowitz, D., \& Limor, Y. (2003). Professional confidence and situational ethics: Assessing the social-professional dialectic in journalistic ethics decisions. Journalism \& Mass Communication Quarterly, 80, 783-801. doi: 10.1177/107769900308000403.

Bernhard, U., \& Dohle, M. (2014). Do even journalists support media restrictions? Presumed political media influences and its consequences. Journalism \& Mass Communication Quarterly, 91, 250-271. doi: 10.1177/1077699014527456.

Boczkowski, P. J. (2004). Digitizing the News: Innovation in Online Newspapers. Cambridge, MA: MIT Press.

Bruns, A. (2008). Blogs, Wikipedia, Second Life, and Beyond. From Production to Produsage. New York: Lang.

Burgoon, J. K., Burgoon, M., Buller, D. B., \& Atkin, C. (1987). Communication practices of journalists: Interaction with public, other journalists. Journalism Quarterly, 64, 125132. doi: $10.1177 / 107769908706400117$

Chaffee, S. H., \& Berger, C. R. (1987). Levels of analysis: An introduction. In: S. H. Chaffee \& C: R. Berger (eds.), Handbook of Communication Science (pp. 143-145). Newbury Park, CA: Sage.

Chaiken, S., Liberman, A., \& Eagly, A. H. (1989). Heuristic and systematic information processing within and beyond the persuasion context. In J. S. Uleman, \& J. A. Bargh (eds.), Unintended Thought: Limits of Awareness, Intention, and Control (S. 212252). New York: Guilford. 
Christians, C. G., Glasser, T. L., McQuail, D., Nordenstreng, K., \& White, R. A. (2009). Normative Theories of the Media: Journalism in Democratic Societies. Urbana, IL: University of Illinois Press.

Cohen, J., \& Tsfati, Y. (2009). The influence of presumed media influence on strategic voting. Communication Research, 36, 359-378. doi: 10.1177/0093650209333026

Cohen, J., Tsfati, Y., \& Sheafer, T. (2008). The influence of presumed media influence in politics: Do politicians' perceptions of media power matter? Public Opinion Quarterly, 72, 331-344. doi: 10.1177/0093650209333026

Coleman, J. S. (1990). Foundations of Social Theory. Cambridge, MA: Belknap.

Coleman, S., \& Ross, K. (2010). The Media and the Public. 'Them' and 'Us' in Media Discourse. Chichester: Wiley-Blackwell.

D’Alessio, D., \& Allen, M. (2000). Media bias in presidential elections: A meta-analysis. Journal of Communication, 50, 133-156. doi: 10.1111/j.1460-2466.2000.tb02866.x

DeWerth-Pallmeyer, D. (1997). The Audience in the News. London: Routledge.

Dohle, M., \& Vowe, G. (2010). Wahrnehmung der politischen Einflüsse von Medienangeboten. Third-Person-Effekte bei Bürgern, Journalisten und Politikern im Vergleich [Perception of political media influences. Third-person effects among citizens, journalists, and politicians in comparison]. In C. Schemer, W. Wirth, \& C. Wünsch (Hrsg.), Politische Kommunikation: Wahrnehmung, Verarbeitung, Wirkung [Political communication: Perception, processing, effects] (pp. 11-30). Baden-Baden: Nomos.

Donsbach, W. (1981). Journalisten zwischen Publikum und Kollegen: Forschungsergebnisse zum Publikumsbild und zum in-group-Verhalten. [Journalists between audience and colleagues. Findings on audience image and in-group behavior]. Publizistik, 29, 168184. 
Donsbach, W. (1983). Journalists' conceptions of their audience. Comparative indicators for the way British and German journalists define their relations to the public. Gazette, 32, 19-36. doi: 10.1177/001654928303200102

Eveland, W. P., \& McLeod, D. M. (1999). The effect of social desirability on perceived media impact: Implications for third-person perceptions. International Journal of Public Opinion Research, 11, 315-333. doi: 10.1093/ijpor/11.4.315

Eveland, W. P., Nathanson, A. I., Detenber, B. H., \& McLeod, D. M. (1999). Rethinking the social distance corollary: Perceived likelihood of expsoure and the third-person perception. Communication Research, 26, 275-302. doi:10.1177/009365099026003001

Fields, J., \& Schuman, H. (1976). Public beliefs about beliefs of the public. Public Opinion Quarterly, 40, 427-448. doi: 10.1086/268330

Fiske, S. T. (2004). Social Beings: A Core Motives Approach to Social Psychology. Chichester: Wiley.

Furnham, A. (1988). Lay Theories: Everyday Understanding of Problems in the Social Sciences. Oxford: Pergamon.

Gans, H. J. (1979): Deciding What's News. A Study of CBS Evening News, NBC Nightly News. Newsweek and Time. New York: Vintage.

Geiß, S., Jackob, N. \& Quiring, O. (2013). The impact of communicating digital technologies: How ICT-journalists conceptualize their influence on the audience and the industry. New Media \& Society, 15, 1058-1076. doi: 10.1177/1461444812465597.

Groeben, N. (1990). Subjective theories and the explanation of human action. In G. R. Semin \& K. J. Gergen (eds.), Everyday Understanding: Social and Scientific Implications. Inquiries in Social Construction (pp. 19-44). Thousand Oaks, CA: Sage. 
Gunther, A. C. \& Storey, J. D. (2003). The influence of presumed influence. Journal of Communication, 53, 199-215. doi: 10.1111/j.1460-2466.2003.tb02586.x

Hanitzsch, T. (2011). Populist disseminators, detached watchdogs, critical change agents and opportunist facilitators. Professional milieus, the journalistic field and autonomy in 18 countries. International Communication Gazette, 73, 477-494. doi:10.1177/1748048511412279

Hartmann, T., \& Dohle, M. (2005). Publikumsvorstellungen im Rezeptionsprozess [Conceptions of the audience in the process of reception]. Publizistik, 50, 287-303. doi: 10.1007/s11616-005-0133-5

Hofstetter, C. R. (1975). Bias in the news: Network television coverage of the 1972 election campaign. Columbus, OH: Ohio State University Press.

Hohlfeld, R. (2003). Journalismus und Medienforschung. Theorie, Empirie, Transfer [Journalism and Media Research: Theory, Empirical Results, Transfer]. Konstanz: UVK.

Kepplinger, H. M. (2007). Reciprocal effects. Towards a theory of mass media effects on decision makers. The Harvard International Journal of Press/Politics, 12, 3-23. doi: 10.1177/1081180x07299798

Kepplinger, H. M., Brosius, H.-B., \& Staab, J. F. (1991). Instrumental actualization: A theory of mediated conflicts. European Journal of Communication, 6, 263-290. doi: $10.1177 / 0267323191006003002$

Kruglanski, A. W. (1989). Lay Epistemics and Human Knowledge. Cognitive and Motivational Bases. New York: Plenum.

Lee, F. L. F., \& Chan, J. M. (2009). The impact of perceived media influence on professional orientations: A survey study of Hong Kong journalists. Full paper presented at the $59^{\text {th }}$ ICA Annual Conference in Chicago, IL, 05-22-2009. 
Lee, T.-T., \& Grimmer, K. (2013). Bias in the news. In W. Donsbach (ed.), The International Encyclopedia of Communication. Retrieved from http://www.communicationencyclopedia.com/subscriber/tocnode.html?id=g97814051 31995_yr2013_chunk_g97814051319957_ss14-1

Li, M. (2013). Journalists' perceptions of media influence in Hong Kong. Full paper presented at the $63^{\text {rd }}$ ICA Annual Conference in London, 06-19-2013.

Loosen, W., \& Schmidt, J.-H. (2012). (Re-)discovering the audience. The relationship between journalism and audience in networked digital media. Information, Communication \& Society, 15, 867-887. doi: 10.1080/1369118x.2012.665467

MacDougall, C. (2003). Learning from differences between ordinary and expert theories of health and physical activity. Critical Public Health, 13, 381-397. doi: $10.1080 / 09581590310001615907$

Meyen, M., \& Riesmeyer, C. (2009). Diktatur des Publikums. Journalisten in Deutschland [Dictatorship of the Audience. Journalists in Germany]. Konstanz: UVK.

Molyneux, L. (2015). What journalists retweet: Opinion, humor, and brand development on Twitter. Journalism, 16, 920-935. doi: 10.1177/1464884914550135

Müller, P. (2013). National identity building through patterns of an international third-person perception in news coverage. International Communication Gazette, 75, 732-749. doi: $10.1177 / 1748048513482546$

Mutz, D. C. (1989). The influence of perceptions of media influence. Third-person effects and public expression of opinions. International Journal of Public Opinion Research, 1, 3-23. doi: 10.1093/ijpor/1.1.3

Napoli, P. M. (2003). Audience Economics. Media Institutions and the Audience Marketplace. New York: Columbia University Press. 
O’Sullivan, J., \& Heinonen, A. (2008). Old values, new media. Journalism role perceptions in a changing world. Journalism Practice, 2, 357-371. doi: $10.1080 / 17512780802281081$

Pan, Z., \& McLeod, J. M. (1991). Multilevel analysis in mass communication research. Communication Research, 18, 140-173. doi: 10.1177/009365091018002002

Perloff, R. M. (1999). The third-person effect: A critical review and synthesis. Media Psychology, 1, 353-378. doi: 10.1207/s1532785xmep0104_4

Petty, R. E., \& Cacioppo, J. T. (1986). Communication and Persuasion: Central and Peripheral Routes to Attitude Change. New York: Springer.

Pool, I. d. S., \& Shulman, I. (1959). Newsmen's fantasies, audiences, and newswriting. Public Opinion Quarterly, 23, 145-158. doi: 10.1086/266860

Price, V., \& Tewksbury, D. (1996). Measuring the third-person effect of news: The impact of question order, contrast, and knowledge. International Journal of Public Opinion Research, 8, 119-141. doi: 10.1093/ijpor/8.2.120

Rössler, P. (2001). Between online heaven and cyberhell: The framing of 'the internet' by traditional media coverage in Germany. New Media \& Society, 3, 49-66. doi: $10.1177 / 14614440122225985$

Scherr, S., Müller, P., \& Fast, V. (2013). Do third-person perceptions amplify exemplification effects? International Journal of Communication, 7, 1603-1621.

Schlesinger, P. (1978). Putting 'Reality’ Together: BBC News. London: Constable.

Schudson, M. (1978). Discovering the News. New York: Basic Books.

Schudson, M. (2000). The sociology of news production revisited (again). In J. Curran \& M. Gurevitch (eds.), Mass Media \& Society (3rd ed., pp. 175-200). London: Arnold. 
Seiter, E. (2003). Lay theories of media effects. Power Rangers at pre-school. In G. Dines \& J. M. Humez (eds.), Gender, Race, and Class in Media. A Text-Reader (2nd ed., pp. 367-384). Thousand Oaks, CA: Sage.

Shen, L., Palmer, J., Mercer Kollar, L. M. \& Comer, S. (2012). A social comparison explanation for the third-person perception. Communication Research, 42, 260-280. doi:10.1177/0093650212467644

Shoemaker, P. J., \& Reese, S. D. (1996). Mediating the Message. Theories of Influences on Mass Media Content (2nd ed.). London: Longman.

Sun, Y., Shen, L., \& Pan, Z. (2008). On the behavioral component of the third-person effect. Communication Research, 35, 257-278. doi: 10.1177/0093650207313167

Tsfati, Y., Cohen, J. \& Gunther, A. C. (2011). The influence of presumed media influence on news about science and scientists. Science Communication, 33, 143-166. doi: $10.1177 / 1075547010380385$

Tsfati, Y., \& Livio, O. (2008). Exploring journalists' perceptions of media impact. Journalism and Mass Communication Quarterly, 85, 113-130. doi:

$10.1177 / 107769900808500108$

van Aelst, P., Brants, K., van Praag, P., de Vreese, C., Nuytemans, M., \& van Daalen, A. (2008). The fourth estate as superpower? An empirical study of perceptions of media power in Belgium and the Netherlands. Journalism Studies, 9, 494-511. doi: $10.1080 / 14616700802114134$

Weaver, D. H., \& Wilhoit, G. C. (1986). The American Journalist. A Portrait of U.S. News People and their Work. Bloomington, IN: Indiana University Press.

Witschge, T. (2012). Changing audiences, changing journalism? In P. Lee-Wright, A. Philips \& T. Witschge (eds.), Changing Journalism (pp. 117-134). London: Routledge. 
Yanovitzky, I. (2002). Effects of news coverage on policy attention and actions: A closer look into the media-policy connection. Communication Research 29, 422-451. doi: $10.1177 / 0093650202029004003$

Yeo, T. E. D. (2016). Communicating legitimacy. How journalists negotiate the emergence of user-generated content in Hong Kong. Journalism \& Mass Communication Quarterly, 93, 609-626. doi: 10.1177/1077699016628823 
Figures

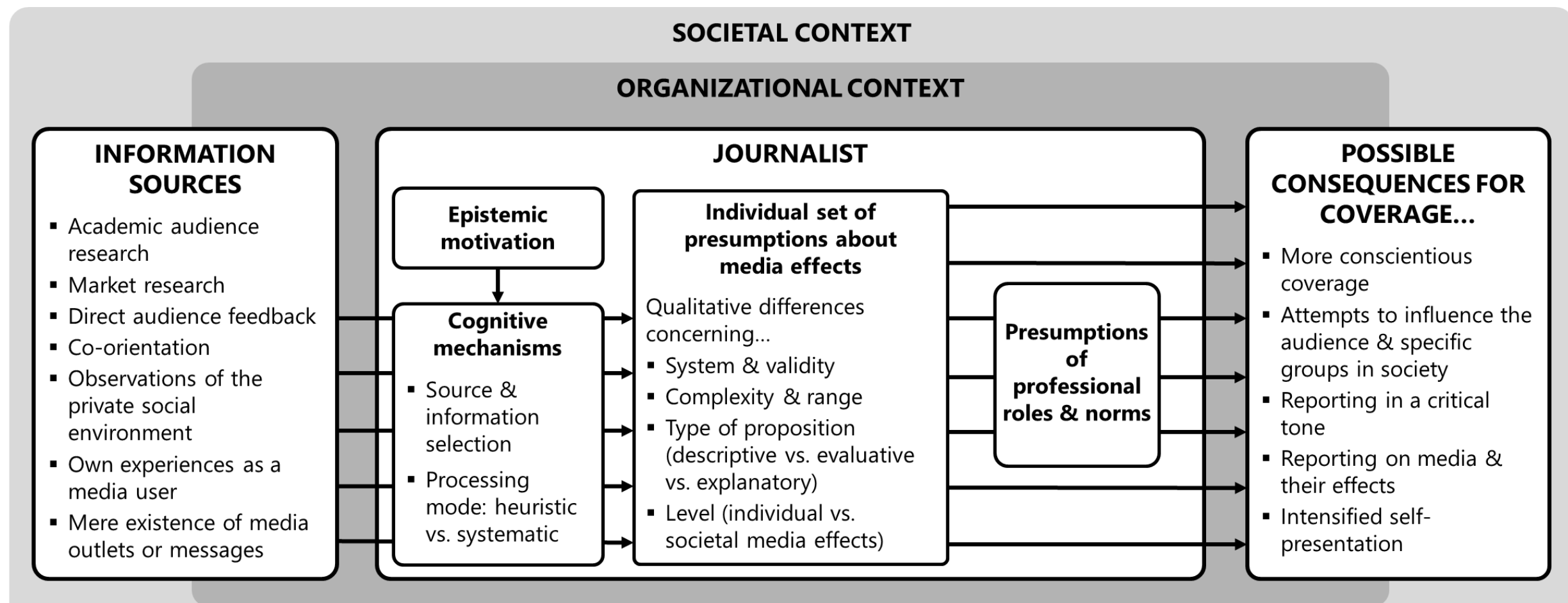

Figure 1. A model of dimensions, determinants, and consequences of journalists' presumptions about media effects 